\title{
Accurate and efficient amino acid analysis for protein quantification using hydrophilic interaction chromatography coupled tandem mass spectrometry
}

\author{
Shrikaar Kambhampati ${ }^{1}$, Jia Li ${ }^{1}$, Bradley S. Evans ${ }^{1 *}$ and Doug K. Allen ${ }^{1,2^{*}}$ (D)
}

\begin{abstract}
Background: Methods used to quantify protein from biological samples are often inaccurate with significant variability that requires care to minimize. The errors result from losses during protein preparation and purification and false detection of interfering compounds or elements. Amino acid analysis (AAA) involves a series of chromatographic techniques that can be used to measure protein levels, avoiding some difficulties and providing specific compositional information. However, unstable derivatives, that are toxic and can be costly, incomplete reactions, inadequate chromatographic separations, and the lack of a single hydrolysis method with sufficient recovery of all amino acids hinder precise protein quantitation using AAA.

Results: In this study, a hydrophilic interaction chromatography based method was used to separate all proteinogenic amino acids, including isobaric compounds leucine and isoleucine, prior to detection by multiple reaction monitoring with LC-MS/MS. Through inclusion of commercially available isotopically labeled $\left({ }^{13} \mathrm{C},{ }^{15} \mathrm{~N}\right)$ amino acids as internal standards we adapted an isotopic dilution strategy for amino acid-based quantification of proteins. Three hydrolysis methods were tested with ubiquitin, bovine serum albumin, (BSA), and a soy protein biological reference material (SRM 3234; NIST) resulting in protein estimates that were $86-103 \%, 82-94 \%$, and $90-99 \%$ accurate for the three protein samples respectively. The methane sulfonic acid hydrolysis approach provided the best recovery of labile amino acids including: cysteine, methionine and tryptophan that are challenging to accurately quantify.

Conclusions: Accurate determination of protein quantity and amino acid composition in heterogeneous biological samples is non-trivial. Recent advances in chromatographic phases and LC-MS/MS based methods, along with the availability of isotopic standards can minimize difficulties in analysis and improve protein quantitation. A robust method is described for high-throughput protein quantification and amino acid compositional analysis. Since accurate measurement of protein quality and quantity are a requirement for many biological studies that relate to crop improvement or more generally, our understanding of metabolism in living systems, we envision this method will have broad applicability.
\end{abstract}

Keywords: HILIC, Chromatography, Isobaric compounds, Amino acids, Protein hydrolysis, Protein quantification, LCMS/MS, Soybeans, Isotopes

\footnotetext{
*Correspondence: Bevans@danforthcenter.org; Doug.Allen@ars.usda.gov

${ }^{1}$ Donald Danforth Plant Science Center, St. Louis, MO, USA
}

Full list of author information is available at the end of the article 


\section{Background}

Proteins are ubiquitous and have enzymatic, structural and storage functions that are essential to life. Enzymes drive the metabolic reactions that sustain cellular activities in plants as well all other lifeforms. For example, Ribulose Bis-phosphate Carboxylase/Oxygenase (RuBisCO), the most abundant enzyme on the planet is integral to photosynthetic processes in plants and produces organic carbon that is needed for food, feed, fuel, fiber and as a feed stock for living organisms. Human and animal diets include significant amounts of protein and require defined levels of essential amino acids obtained predominantly from proteins derived from plants. Proteins in the form of antibodies are crucial to immune defense whereas structural proteins help define cellular and subcellular compartmentation and organization. These proteins provide physical support or function as membrane-spanning transporters that enable passage of metabolites and salts. Given the importance of proteins, methods to quantify protein are widespread; yet accurate measurement of protein and amino acids in biomass is non-trivial and relies on assumptions about composition and losses, owing to the variance in chemical and physical properties of proteins and biological matrices.

The most common methods for the quantification of total protein include: combustion-based carbon to nitrogen ratio $(\mathrm{C} / \mathrm{N})$ analysis using isotope ratio mass spectrometry (IRMS) or other elemental analysis techniques, the Kjeldahl method of titration, and biuret assays such as Lowry's method [1], Bradford method [2] and bicinchoninic acid approach [3]. C/N-based IRMS [4] and Kjeldahl [5] analyses are sensitive and reproducible based on the extent of chemical reactions involved in tissue pyrolysis and hydrolysis, however artefacts can occur (e.g. melamine contamination or adulteration) and protein quantification requires a presumed amino acid description (i.e. Jones factor; [6, 7]). Spectrophotometric and colorimetric approaches can be used for determining protein levels but are subject to interference from other compounds [8-11]. Thus, spectrophotometry is limited to detection and quantification of soluble protein in conditions compatible with the respective assay and is based on strategies for protein purification that are widespread [9]. Some protein will be lost as a result of purification, so whether the goal is to measure total or a specific protein is important to establish prior to choosing a method. In addition, the amino acid composition and sequence affect the accuracy of spectrophotometric methods, thus a primary application is the quantification of a known pure protein relative to a measured standard or relative comparison between like samples. Importantly, none of the described methods measure amino acid composition.
Amino acid compositional analysis (AAA) can be used to assess protein levels (i.e. when proteins are hydrolyzed) or to identify proteins as a complementary approach to peptide mass finger printing or MS/MS sequencing [12]. The quality of protein is determined by the amino acid composition and hence AAA can guide plant breeding and engineering efforts to enhance food, feed, nutraceutical and pharmaceutical applications. Amino acids with or without derivatization are separated utilizing, (ultra) high performance liquid chromatography (UHPLC/UPLC or HPLC)-, gas chromatography (GC) or capillary electrophoresis (CE) prior to detection by absorbance, fluorescence, or mass spectrometry (MS). As an example, when primary amines react with fluoraldhyde o-phthaldialdehyde (OPA), a derivatizing reagent, isoindoles are formed and contain a fluorophore excited at 302-395 $\mathrm{nm}$ and detected at 420-650 nm [13]. Fluorescence-based detection can achieve limits $<1$ pmol [13-16]; but the derivatives have limited stability [17] and measurement can be additionally compromised by interfering signals from naturally fluorescing compounds. MS linked to GC (i.e. GC-MS) can circumvent the latter but routine derivatizations such as silylation [18] that enhances compound volatility also reduces stability $[19,20]$, and may degrade amino acids or produce multiple reaction products that complicate analyses. In addition, the derivatized standards must be made fresh prior to each analysis.

Liquid chromatography does not require derivatizations to enhance volatility and when coupled with tandem mass spectrometry (LC-MS/MS) provides a burgeoning set of hyphenated techniques to complement polar compound analysis. LC-MS/MS has high selectivity and is sensitive to detection of both derivatized [21] and underivatized amino acids [22, 23]; however, the coupling of LC with MS is restricted to compatible volatile solvents unless additional desalting processes are introduced. LC-MS/MS has enabled rapid throughput with reverse phase columns to resolve most amino acids [24]. Ion pair reagents $[25,26]$ further improve the resolution but contaminate the MS system, resulting in suppressed signals and affecting sensitivity for other applications.

Hydrophilic interaction liquid chromatography (HILIC) columns can potentially avoid these difficulties. HILIC columns partition contents between a mobile phase that is significantly hydrophobic with a stationary phase that is sufficiently hydrophilic to retain partially water-soluble compounds [27]. The retention of polar compounds aids separation [28-30], and in some cases has enabled the resolution of isobaric compounds $[31,32]$. Recently, HILIC based approaches have been used for successful resolution of both proteinogenic [31, 33-36] and non-proteinogenic [37-39] amino acids for animal and plant matrices. By pairing with tandem 
mass spectrometry, HILIC could be used to sensitively detect and quantify protein content without the need for chromophore additions or other derivatizations and would enable resolution of all amino acid isotopologues when metabolic applications with isotopic labeling are of interest. Specifically, the masses of labeled (1) asparagine, aspartate, leucine, and isoleucine, (2) valine, threonine, proline, and cysteine and (3) glutamate, glutamine, lysine and methionine overlap, therefore chromatographic separation are necessary to avoid ambiguous results.

In this study, a HILIC-tandem MS approach was used to assess free amino acids and tested with multiple hydrolysis techniques to quantify protein level and composition by an isotope dilution strategy. All twenty amino acids were quantified using commercially available isotope labeled internal standards within a linear range of four orders of magnitude that accurately accounts for losses in signal intensities, interference from the biological matrix, and degradation that otherwise are problematic $[25,40]$. Recovery of labile amino acids including cysteine, methionine and tryptophan is particularly germane because these are frequently the focus of efforts to improve nutrition. $\mathrm{A}{ }^{13} \mathrm{C},{ }^{15} \mathrm{~N}$ uniformly labeled amino acid standard mixture that contained all twenty proteinogenic amino acids as internal standards was spiked into samples for absolute quantification and to assess amino acid degradation and losses during sample preparation. The method includes sample preparation, chromatographic resolution and mass spectrometric detection of amino acids and does not require costly, toxic, and sometimes proprietary chemical derivatization reagents that produce unstable products, give variable reaction efficiencies and require significant sample preparation time that reduces throughput. The MS approach avoids ambiguity because quasi-molecular ion masses (mass-tocharge ratios also could be used) not chromophores are detected. Thus, small retention time drifts do not require additional external standard runs. The studies indicate that hydrolysis is complete $(86-103 \%)$ and that protein can be accurately quantified with the prescribed isotopic dilution-based analysis without the need for additional experiments to assess more labile amino acids as in other AAA methods.

\section{Methods}

\section{Reagents and materials}

${ }^{13} \mathrm{C},{ }^{15} \mathrm{~N}$ isotopically labeled amino acid standards were obtained as a cell free amino acid mixture (SigmaAldrich, St. Louis, Missouri, USA). Amino acid standard curves were generated using Thermo Scientific ${ }^{\mathrm{TM}}$ Pierce $^{\mathrm{TM}}$ Amino acid standard $\mathrm{H}$ (Fisher Scientific, Fair Lawn, New Jersey, USA) with the addition of tryptophan (Sigma-Aldrich, St. Louis, Missouri, USA) HPLC grade acetonitrile was purchased from Fisher Bioreagents ${ }^{\mathrm{TM}}$ (Fisher Scientific, Fair Lawn, New Jersey, USA). Ammonium formate (99\%), obtained from Acros Organics (New Jersey) was dissolved and combined with ultrapure water and HPLC grade acetonitrile (Fisher Scientific, Fair Lawn, New Jersey, USA) to make solvents A and B and then filtered through $0.2 \mu \mathrm{m}$ Durapore ${ }^{\circledR}$ membrane filters (Millipore-Sigma, Burlington, Massachusetts, USA) prior to use. Ubiquitin and bovine serum albumin protein standards were obtained from Sigma-Aldrich (St. Louis, Missouri, USA). Hydrolysis reagents including: $6 \mathrm{M} \mathrm{HCl}$ (24308), 4 M methane sulfonic acid solution with $0.2 \%$ tryptamine (w/v) (M4141) and hydrogen peroxide (16911) were from Sigma-Aldrich (St. Louis, Missouri, USA). Soy flour standard reference material ${ }^{\circledR} 3234$, was purchased from National Institute of Standards and Technology (NIST, Gaithersburg, Maryland, USA). The hydrolysis/derivatization vial used for all hydrolyses procedures were a Kimble ${ }^{\circledR}$ product (Vineland, New Jersey, Part \# 896820).

\section{HPLC-MS/MS instrumentation, chromatographic and MS parameters}

All samples were separated and analyzed using a Shimadzu Prominence-xR UFLC (UPLC) system connected to a SCIEX hybrid triple quadrupole-linear ion trap MS equipped with Turbo $\mathrm{V}^{\mathrm{TM}}$ electrospray ionization (ESI) source. Positive ion mode was used for all amino acids, except cysteic acid which was ionized in negative mode. A $3 \mu$ sample was injected on the Infinity Lab Poroshell 120 Z-HILIC column $(2.7 \mu \mathrm{m}, 100 \times 2.1 \mathrm{~mm}$; Agilent Technologies, Santa Clara, CA, USA) and amino acids were eluted with an increasing gradient of $20 \mathrm{mM}$ ammonium formate in water (A) and acetonitrile: water (90:10) at a final concentration of $20 \mathrm{mM}$ ammonium formate (B), pH 3.0 for both solvents. A constant flow of $0.25 \mathrm{~mL} /$ min was provided to separate amino acids through gradient elution, of $100-90 \%$ B over $2 \mathrm{~min}$ and then to $50 \%$ B over the next 6 min followed by returning to $100 \%$ B over $30 \mathrm{~s}$ before re-equilibrating the column for $6.5 \mathrm{~min}$. Electrospray ionization source conditions included: ion spray voltage, $4.5 \mathrm{kV}$ (ESI+ and ESI-); ion source temperature, $400^{\circ} \mathrm{C}$; source gas 1,45 ; source gas 2,40 ; and curtain gas, 35 . Ions were detected and monitored using a targeted MRM approach with the parameters listed in Additional file 1: Table S1 based on direct injections of individual amino acid standards. Data were analyzed using the quantitation wizard available in Analyst (v. 1.6.2) software (SCIEX, Concord, Canada). Amino acid concentrations and losses were calculated from direct comparison of analyte peak areas relative to isotope labeled internal standards. 


\section{Comparison of protein hydrolysis techniques}

Seven hydrolysis methods were initially compared using $6 \mathrm{M} \mathrm{HCl}$ or $4 \mathrm{M}$ methane sulfonic acid with a combination of oxidizing agents (hydrogen peroxide, performic acid) and antioxidants (beta-mercaptoethanol $(\beta-\mathrm{ME})$, phenol, tryptamine) (Additional file 2: Figure S1) [4147]. All hydrolyses were performed in a hydrolysis/derivatization vial (Kimble ${ }^{\circledR}$, Vineland, NJ) that was purged with nitrogen and evacuated prior to heating. From the initial studies a subset of three approaches were further characterized. In the first method, hydrogen peroxide $\left(\mathrm{H}_{2} \mathrm{O}_{2} ; 30 \% \mathrm{v} / \mathrm{v}\right)$ was used to oxidize susceptible amino acids at $30{ }^{\circ} \mathrm{C}$ for $30 \mathrm{~min}$ followed by vapor phase hydrolysis with $6 \mathrm{M} \mathrm{HCl}\left(24 \mathrm{~h}\right.$ at $\left.110{ }^{\circ} \mathrm{C}, 0.4 \% \beta-\mathrm{ME}, \mathrm{v} / \mathrm{v}\right)$. A second approach included hydrolysis without oxidation and the third strategy included $4 \mathrm{M}$ methane sulfonic acid containing $0.2 \%$ tryptamine $\left(110{ }^{\circ} \mathrm{C}\right.$ for $\left.22 \mathrm{~h}\right)$. Protein standards were hydrolyzed in triplicate in $350 \mu \mathrm{l}$ flat bottom glass inserts tubes within the vacuum chamber. At the end of the hydrolysis, samples were brought to room temperature, neutralized with $4 \mathrm{M} \mathrm{NaOH}$, and dried in a speed vacuum centrifuge. Ultrapure water was used to solubilize amino acids prior to filtering $(0.45 \mu \mathrm{m}$ cellulose acetate centrifuge filters, $\operatorname{costar}^{\circledR}$, Corning Inc.) and storing at $-80{ }^{\circ} \mathrm{C}$ until use. Protein quantification by AAA was assessed relative to weighed values and known compositions. Soy flour standard reference material ${ }^{\circledR} 3234$, obtained from NIST was compared to the certificate of analysis (CoA) [48].

\section{Derivatization with AccQ-Tag and UPLC based detection}

AccQ-Tag derivatization, detection, and quantification were carried out using the manufacturer's protocol. In brief, the 6-aminoquinolyl-N-hydroxysuccinimidyl carbamate (AQC) reagent was reconstituted in $1 \mathrm{~mL}$ acetonitrile and heated at $55{ }^{\circ} \mathrm{C}$ until dissolved completely. Aliquots were combined with AccQFlour borate buffer and reconstituted $A Q C$ reagent, incubated at room temperature then heated to $55^{\circ} \mathrm{C}$ for $10 \mathrm{~min}$ prior to transferring into amber glass vials for HPLC injection.

Sample analysis included a Waters UPLC system with a UPLC Binary Solvent Manager and Sample Manager equipped with a Cortecs UPLC C18 $(1.7 \mu \mathrm{m}$, $2.1 \times 100 \mathrm{~mm}$ ) column. The solvents used were the manufacturer-supplied AccQ-Tag Ultra Eluent A and AccQTag Ultra Eluent B. The binary gradient involved a brief hold at $0.1 \%$ for $54 \mathrm{~s}$ followed by increasing \%B to 9.1 over $5.74 \mathrm{~min}$ and then to 21.2 until $7.74 \mathrm{~min}$. The column was then flushed by increasing the $\% \mathrm{~B}$ to 59.6 by $8.04 \mathrm{~min}$ and holding until $8.64 \mathrm{~min}$. The $\% \mathrm{~B}$ contribution was then reduced to 0.1 by $8.73 \mathrm{~min}$ and the column equilibrated for $0.77 \mathrm{~min}$. Amino acids were detected by photodiode array and quantification based on standard curves generated with Thermo Scientific ${ }^{\mathrm{TM}}$ Pierce $^{\mathrm{TM}}$ amino acid standard $\mathrm{H}$ (Fisher Scientific, Fair Lawn, New Jersey, USA) including the addition of tryptophan, cysteic acid and methionine sulfoxide standards at known levels (Sigma-Aldrich, St. Louis, Missouri, USA).

\section{Results and discussion}

\section{Proteinogenic amino acids can be resolved using HILIC}

Protein determination from complex biomass samples is challenging and requires preparative methods that are not biased by differences in protein solubility. In addition, accurate quantification of protein requires knowledge of the amino acid composition which therefore must be determined for each sample. To address the latter, a 15-min LC method was developed with a binary gradient composed of $20 \mathrm{mM}$ ammonium formate in water (A) and $20 \mathrm{mM}$ ammonium formate in acetonitrile: water (90:10) (B) adjusted to $\mathrm{pH} 3.0$. The 20 proteogenic

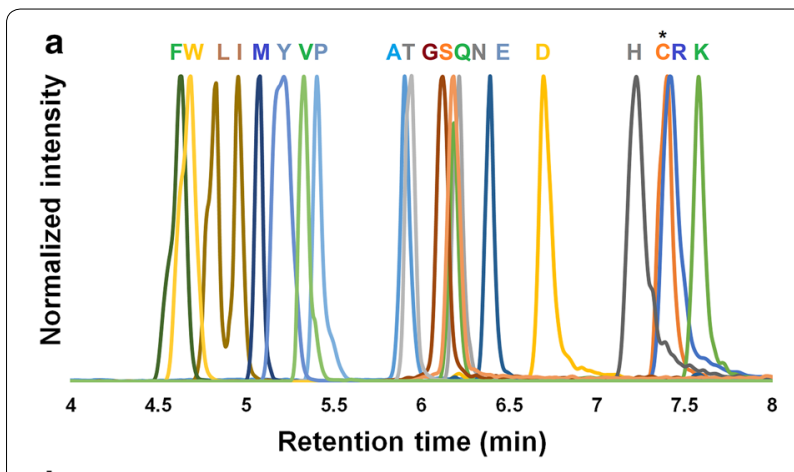

b

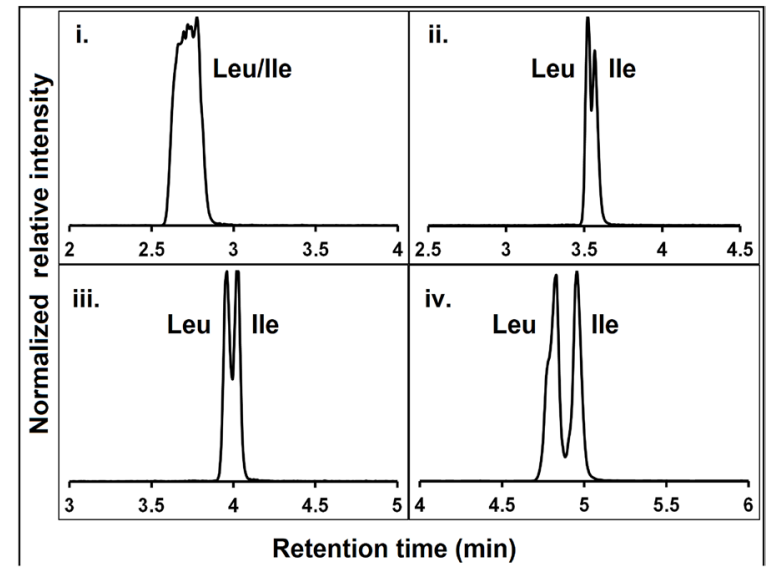

Fig. 1 a Chromatographic separation of twenty amino acids using a Z-HILIC column b. Leucine and isoleucine were separated capitalizing on the HILIC-water layer. (i) Leucine and isoleucine are not resolved with a linear gradient $10-50 \%$ solvent A over eight minutes. (ii-iv) Represent increased separation of these compounds with changes in gradient over the first 2 min (ii 0-25\% solvent A, iii 0-15\% solvent A, iv 0-10\% solvent A). *Cysteine was detected as cystine. Ile was quantified using a distinct mass trace (Additional file 1: supplementary Table 1) 
amino acids (Fig. 1a) were resolved chromatographically; through a solvent gradient profile that included initiating runs with $100 \%$ solvent $B(0.25 \mathrm{~mL} / \mathrm{min})$, transitioning to $10 \%$ solvent $\mathrm{A}$ within 2 min, then to $50 \%$ solvent $\mathrm{A}$ over $6 \mathrm{~min}$. Amino acids were eluted within this period and the initial conditions were re-established within $30 \mathrm{~s}$ followed by equilibration for $6.5 \mathrm{~min}$. Chromatographic resolution of leucine (Leu) and isoleucine (Ile), that are isobaric and challenging to separate, was used to benchmark the method. The water partitioning capacity of HILIC columns included $0-10 \%$ solvent A to separate the isobars [Fig. $1 \mathrm{~b}(\mathrm{i}-\mathrm{iv})]$. Unlike reverse phase chromatography methods paired with modifiers [21, 24-26], this approach can be adapted to existing liquid chromatography systems without requiring extensive instrument clean-up time.

\section{Quantitative amino acid signal responses extend over four orders of magnitude using ${ }^{15} \mathrm{~N}{ }^{13} \mathrm{C}$ labeled internal standards}

Eluted amino acids were ionized by an electrospray approach (ESI) and detected using a multiple reaction monitoring (MRM) method (parameters described in
Additional file 1: Table S1). Amino acids were monitored as positive ions except for the oxidized form of cysteine, cysteic acid, which was detected in negative ion mode. Peak areas of an equimolar unlabeled standard mix were integrated and normalized to that of the largest peak, phenylalanine, to obtain relative response factors (Table 1). The differences in matrix effects and ion suppression for individual amino acids preclude the use of a single internal standard, such as norvaline [15, 49, 50] thus a commercially available mix of uniformly ${ }^{13} \mathrm{C}$, ${ }^{15} \mathrm{~N}$ labeled amino acids was used as internal standards enabling an isotopic dilution strategy. When labeled internal standards are provided the changes in instrument performance and operation, sensitivity, influences of sample matrix, and losses during sample preparation are accounted for such that the ratio of analyte to internal standard is maintained and the amount of a compound can be quantified accurately without continually regenerating external calibration curves. A serial dilution of an unlabeled amino acid standard mixture (0.1-1000 pmol) spiked with a constant amount of internal standard mix (20 pmol) was prepared and the ratio of analyte to internal standard used to generate a standard curve for each

Table 1 Performance characteristics of $\mathbf{2 0}$ amino acids for quantitative analysis

\begin{tabular}{|c|c|c|c|c|c|c|}
\hline & Retention time & aRRF & ${ }^{b}$ LOD (pmol) & ${ }^{\circ} \mathrm{LOQ}$ (pmol) & $\operatorname{Min}(p m o l)^{d}$ & $\operatorname{Max}(p m o l)^{d}$ \\
\hline Alanine & 5.90 & 0.59 & 11.62 & 35.21 & 0.50 & 1000 \\
\hline Arginine & 7.41 & 42.39 & 0.83 & 2.53 & 0.10 & 1000 \\
\hline Asparagine & 6.22 & 3.71 & 5.55 & 16.81 & 0.20 & 1000 \\
\hline Aspartate & 6.69 & 4.66 & 7.76 & 23.52 & 0.30 & 1000 \\
\hline Cystine & 7.38 & 5.83 & 0.20 & 0.61 & 0.15 & 750 \\
\hline Glutamine & 6.18 & 1.39 & 0.04 & 0.12 & 0.03 & 150 \\
\hline Glutamate & 6.39 & 9.42 & 0.44 & 1.32 & 0.10 & 1000 \\
\hline Glycine & 6.11 & 0.34 & 8.42 & 25.53 & 2.50 & 1000 \\
\hline Histidine & 7.22 & 51.16 & 1.18 & 3.58 & 0.10 & 1000 \\
\hline Isoleucine & 4.95 & 9.87 & 0.14 & 0.42 & 0.10 & 1000 \\
\hline Leucine & 4.83 & 57.03 & 1.73 & 5.23 & 0.10 & 1000 \\
\hline Lysine & 7.58 & 24.58 & 2.55 & 7.72 & 0.50 & 1000 \\
\hline Methionine & 5.08 & 10.77 & 0.10 & 0.30 & 0.10 & 1000 \\
\hline Phenylalanine & 4.63 & 100.00 & 1.15 & 3.49 & 0.10 & 1000 \\
\hline Proline & 5.40 & 96.77 & 0.78 & 2.36 & 0.10 & 1000 \\
\hline Serine & 6.18 & 3.91 & 9.24 & 28.01 & 2.50 & 1000 \\
\hline Threonine & 5.94 & 6.31 & 5.83 & 17.68 & 0.50 & 1000 \\
\hline Tryptophan & 4.68 & 42.97 & 1.03 & 3.13 & 0.10 & 1000 \\
\hline Tyrosine & 5.24 & 9.42 & 1.29 & 3.90 & 0.10 & 1000 \\
\hline Valine & 5.33 & 28.45 & 0.49 & 1.48 & 0.10 & 1000 \\
\hline
\end{tabular}

a $\mathrm{RRF}$ represents response factors relative to phenylalanine which showed a maximum response. $\mathrm{RRF}=100 *\left(\right.$ Peak Area $\left.\frac{\text { analyte }}{\text { Phenylalanine }}\right)$

b $L O D=3.3 \times \sigma /$ slope of the standard curve

c $L O Q=10 \times \sigma /$ slope of the standard curve

d range of concentrations examined

( $\sigma=\mathrm{SD}$ of peak areas of least detectable concentration, $n=3$ ) 
of the amino acids (Additional file 3: Figure S2). Then the linear range, limits of detection (LOD) and quantification (LOQ) were determined for each amino acid as described in Table 1.

Fifteen of the twenty proteinogenic amino acids had LODs less than 3 pmol injected on column. Glycine, alanine and serine had higher LODs of 8.42, 11.62 and 9.24 pmol respectively (Table 1 ) that reflect ionization efficiencies and possibly signal suppression from matrix, solvent, or salt clusters. Despite the differences, the isotope dilution strategy produced reproducible results because the factors contributing to variability affected the amino acids in unlabeled samples as well as the internal standards.

Proteins can be accurately quantified using multiple hydrolysis methods with internal labeled standards

Protein hydrolysis efficiency and processing losses were assessed by quantifying a known amount of a protein standard. A preliminary hydrolysis test was performed using seven different methods described in literature [41-47] based on a combination of reaction conditions, with agents to promote or diminish oxidative reactions that maximize sensitive amino acid detection (Additional file 2: Figure S1). Three methods that gave maximal recovery and had low standard errors for most of the amino acids were further pursued. Detection of the most labile amino acids is presented in Additional file 2: Figure $\mathrm{S} 1$. As described in the methods, hydrolysis with either $6 \mathrm{M} \mathrm{HCl}$ or $4 \mathrm{M}$ methane sulfonic acid was performed in combination with hydrogen peroxide $\left(\mathrm{H}_{2} \mathrm{O}_{2}\right)$ to induce oxidation or $0.4 \% \beta-\mathrm{ME}$ or $0.2 \%$ tryptamine as antioxidants for reliable peak quantitation. The AAA and protein hydrolysis approaches were evaluated using BSA and ubiquitin standards.

The protein standards were greater than 98\% pure (vendor supplied quality control values) therefore, comparison of a known amount of protein with that calculated after hydrolysis and LC-MS/MS analysis provided a strategy to accurately assess protein quantification. Aliquots of labeled amino acid standards were included with each hydrolysis to control for individual losses during the process. Each amino acid was quantified through the ratio of analyte peak area relative to the equivalent isotopically labeled $\left({ }^{13} \mathrm{C},{ }^{15} \mathrm{~N}\right)$ internal standard. Total protein concentration was calculated as the sum of individual amounts of amino acids. The amount of two protein standards was $86-103 \%$ of the known value for ubiquitin and $82-94 \%$ for BSA depending on the hydrolysis approach (Table 2).

Though accounted for through the isotopic dilution strategy, losses for individual amino acids were determined by comparing peak areas of isotopically labeled standards with or without prior hydrolysis (Fig. 2). Since the amino acid standards do not require hydrolysis the comparison indicates the extent of amino acid degradation during the process. When quantitative hydrolysis is desired [15, 46, 47] the time needed to break all peptidyl bonds can result in additional side chemical reactions that alter or degrade amino acids. Single point calibrants that normalize for losses in signal intensity such as: norvaline, norleucine, alpha-amino butyric acid or sarcosine have distinct responses and therefore cannot account for the differences in specific amino acids [15]. Standard addition methods (i.e. spiking in known amounts of each standard) can account for differences in response but

Table 2 Quantitation of ubiquitin and BSA standards as determined by LC-MS/MS isotope dilution and AccQ-Tag methods

\begin{tabular}{|c|c|c|c|}
\hline & $\mathrm{H}_{2} \mathrm{O}_{2}+6 \mathrm{M} \mathrm{HCl}+\beta-\mathrm{ME}$ & $6 \mathrm{M} \mathrm{HCl}+\beta-\mathrm{ME}$ & $\begin{array}{l}4 \mathrm{M} \\
\text { MetS }+0.2 \% \\
\text { Tryptamine }\end{array}$ \\
\hline \multicolumn{4}{|c|}{$\%$ Quantitation of actual* value using LC-MS/MS } \\
\hline Ubiquitin & $86.7 \pm 8.5$ & $100.8 \pm 0.3$ & $103.0 \pm 0.7$ \\
\hline \multirow[t]{2}{*}{ BSA } & $82.4 \pm 0.8$ & $92.7 \pm 1.3$ & $94.6 \pm 0.5$ \\
\hline & $\mathrm{H}_{2} \mathrm{O}_{2}+6 \mathrm{M} \mathrm{HCl}+\beta-\mathrm{ME}$ & $6 \mathrm{M} \mathrm{HCl}+\beta-\mathrm{ME}$ & $\begin{array}{l}4 \mathrm{M} \\
\text { MetS + 0.2\% } \\
\text { Tryptamine }\end{array}$ \\
\hline \multicolumn{4}{|c|}{ \% Quantitation of actual* value using AccQ-Tag } \\
\hline Ubiquitin & $79.6 \pm 9.7$ & $88.9 \pm 0.5$ & $48.8 \pm 9.4$ \\
\hline BSA & $80.5 \pm 1.1$ & $59.3 \pm 7.9$ & $14.6 \pm 5.1$ \\
\hline
\end{tabular}

Variability is expressed as standard error of mean $(n=3)$

$\mathrm{H}_{2} \mathrm{O}_{2}$ hydrogen peroxide, $\mathrm{HCl}$ hydrochloric acid, $\beta-M E$ beta-mercaptoethanol, MetS methane sulfonic acid

${ }^{*}$ Actual values are based on weighed amount of standards 


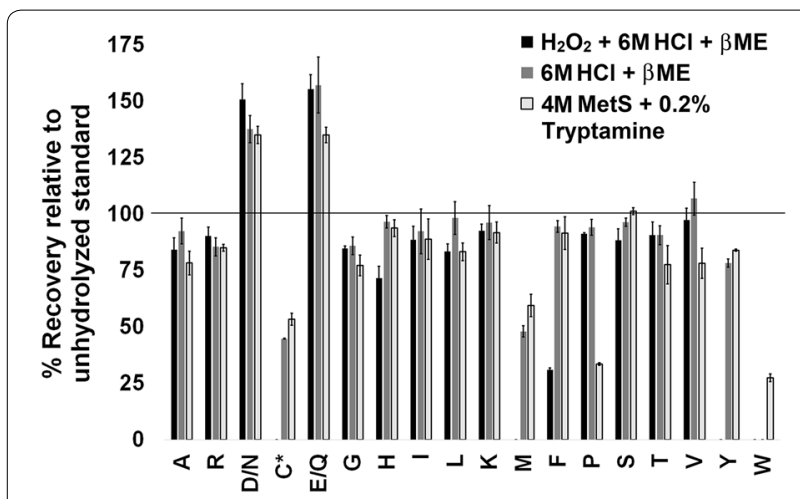

Fig. 2 Quantitation of individual amino acids upon hydrolysis using three different methods. ${ }^{13} \mathrm{C},{ }^{15} \mathrm{~N}$ labeled amino acid standards were hydrolyzed and compared to an unhydrolyzed standard. *Cysteine was detected as cystine. D/N represents the combination of aspartate and asparagine detected as aspartate, E/Q represents the combination of glutamate and glutamine detected as glutamate

require twice the number of samples and increase time and cost $[49,50]$.

Comparison of standards with and without hydrolysis indicated significant degradation of a small number of amino acids including cysteine, methionine and tryptophan [41-45]. Other amino acids had losses of approximately $25 \%$ or less in most cases (Fig. 2). Asparagine and aspartate, glutamine and glutamate were analyzed together because asparagine and glutamine are deamidated during the hydrolysis process. Deamidation of asparagine and glutamine to the corresponding carboxylic acids does not significantly impact quantification of total protein because the molecular masses are near equivalent (i.e. asparagine is $132 \mathrm{~g} / \mathrm{mol}$, aspartate is $133 \mathrm{~g} / \mathrm{mol}$, glutamine is $146 \mathrm{~g} / \mathrm{mol}$ and glutamate is $147 \mathrm{~g} / \mathrm{mol}$ ). Cysteine (Cys), methionine (Met) and tryptophan (Trp) are susceptible to oxidative degradation during hydrolysis resulting in variable recovery. These three amino acids are important targets for bioengineering and crop improvement, due to their relative low content in soybean protein despite being a rich source of other essential amino acids [51]; therefore, quantification of the labile amino acids was scrutinized during the method development. Hydrolysis with $6 \mathrm{M} \mathrm{HCl}$ and $4 \mathrm{M}$ methane sulfonic acid resulted in 45 and 53\% of Cys and 48 and $60 \%$ of Met respectively without producing significant cysteic acid and methionine sulfoxide. When protein was treated with $\mathrm{H}_{2} \mathrm{O}_{2}$ prior to hydrolysis the stable oxidized forms were generated. Trp was completely degraded in both methods that used $6 \mathrm{M} \mathrm{HCl}$ for hydrolysis, [52], while the methane sulfonic acid method, with $0.2 \%$ tryptamine resulted in a $27 \%$ recovery (Fig. 2) qualitatively similar to prior reports [53]. Phenylalanine losses were significant in $6 \mathrm{M} \mathrm{HCl}$ method that was subject to prior oxidation compared to the other two methods, and tyrosine (Tyr) was not detected, likely due to halogenation [54]. Proline losses due to processing and degradation were also significant, however even when present in significantly reduced quantities the amount of amino acids could be accurately assessed through the isotopic dilution strategy (Tables 2, 3).

\section{AccQ-Tag based protein quantitation requires parallel processing and multiple runs for accurate results}

For comparison, proteins were also quantified using a commercially available UPLC system (AccQ-Tag) based on AQC derivatives detected by photodiode array (PDA). When the protein quantity was calculated by the sum of all amino acid amounts, the results were variable and significantly underestimated the total protein level (i.e. $48-90 \%$, and $15-81 \%$ for ubiquitin and BSA respectively) depending on the hydrolysis approach (Table 2).

The low protein estimates from the AccQ-Tag method reflect losses that could not be accounted for during hydrolysis and processing. The AccQ-Tag method is typically used to establish relative amino acid composition and involves several preparations (using different

Table 3 Calculated amounts of labile amino acids, after different hydrolyses, represented in percentage of total protein, BSA

\begin{tabular}{|c|c|c|c|c|c|c|c|}
\hline \multirow[t]{2}{*}{ Analyte } & \multirow[t]{2}{*}{ Expected (\%) } & \multicolumn{3}{|c|}{ Observed (\%, LC-MS/MS) } & \multicolumn{3}{|c|}{ Observed (\%, AccQ-Tag) } \\
\hline & & $\begin{array}{l}\mathrm{H}_{2} \mathrm{O}_{2}+6 \mathrm{M} \\
\mathrm{HCl}+\beta-\mathrm{ME}\end{array}$ & $6 \mathrm{M} \mathrm{HCl}+\beta-\mathrm{ME}$ & $\begin{array}{l}4 \mathrm{M} \text { MetS }+0.2 \% \\
\text { tryptamine }\end{array}$ & $\begin{array}{l}\mathrm{H}_{2} \mathrm{O}_{2}+6 \mathrm{M} \\
\mathrm{HCl}+\beta-\mathrm{ME}\end{array}$ & $6 \mathrm{M} \mathrm{HCl}+\beta-\mathrm{ME}$ & $\begin{array}{l}4 \mathrm{M} \\
\text { MetS }+0.2 \% \\
\text { tryptamine }\end{array}$ \\
\hline Cys* & 5.77 & $5.3 \pm 0.51$ & $4.23 \pm 0.32$ & $4.56 \pm 0.34$ & $5.38 \pm 0.10$ & $1.11 \pm 0.06$ & $1.75 \pm 0.32$ \\
\hline Met* & 0.82 & ND & $0.79 \pm 0.01$ & $0.76 \pm 0.01$ & $1.52 \pm 0.02$ & $0.29 \pm 0.01$ & $0.46 \pm 0.02$ \\
\hline Trp & 0.49 & ND & ND & $0.59 \pm 0.02$ & $0.04 \pm 0.00$ & $0.05 \pm 0.00$ & $0.23 \pm 0.01$ \\
\hline
\end{tabular}

Variability is expressed as standard error of mean $(n=3) . N D$, not detected

${ }^{*}$ Cysteine was measured as cysteic acid in hydrolysis that involved prior oxidation and as cystine otherwise. Similarly, methionine was measured as methionine sulfoxide upon oxidation and as methionine in the two methods that did not involve prior oxidation 


\section{AccQ-Tag}
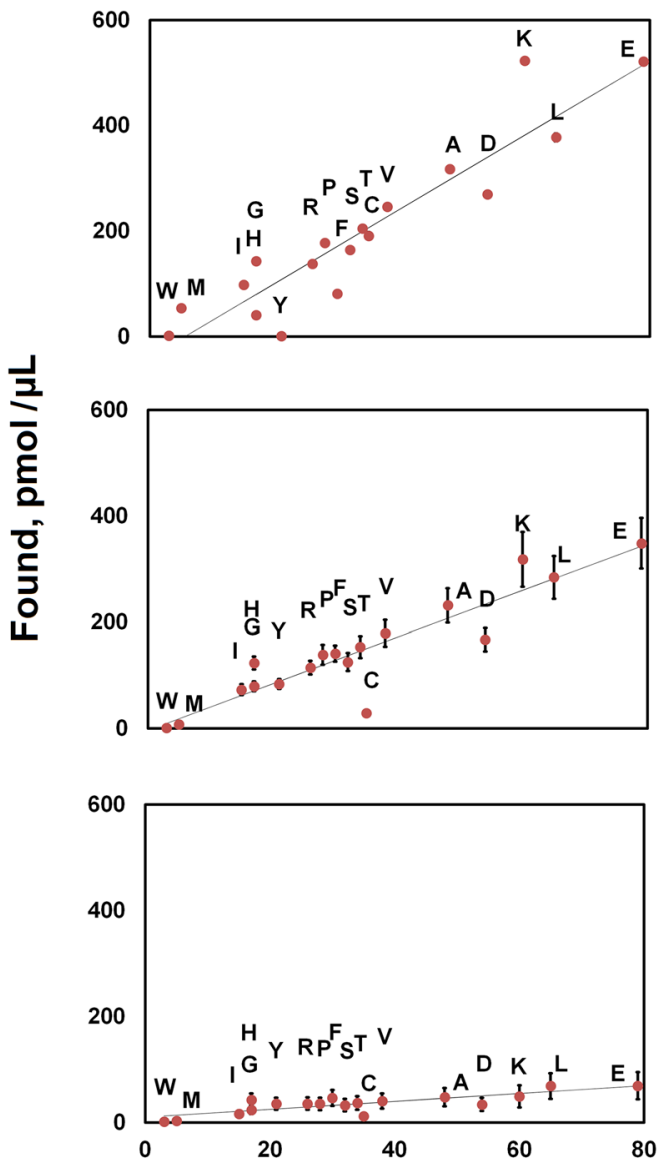

HILIC-MS/MS
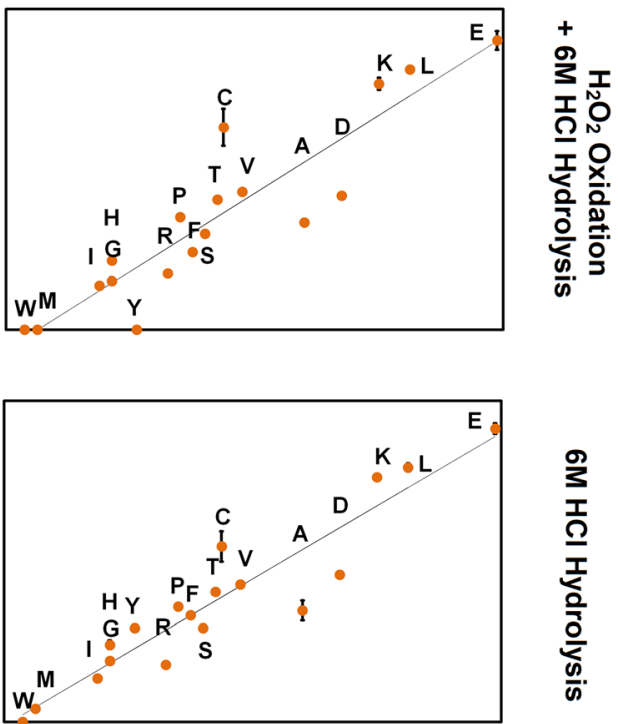

$\frac{9}{3}$
$\frac{1}{\Omega}$
$\frac{1}{1}$
$\frac{0}{5}$
$\frac{0}{0}$
$\frac{0}{n}$

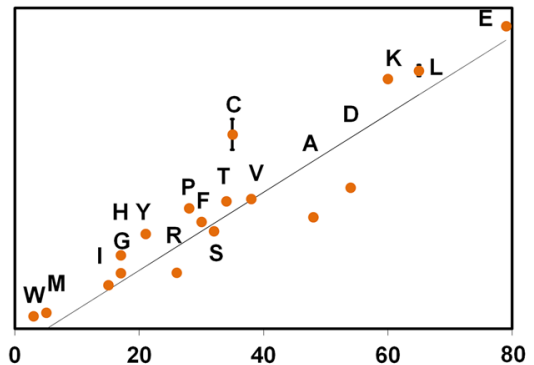

\section{Number of Residues (pmol per pmol protein)}

Fig. 3 Quantitative comparison of amino acids using AccQ-Tag and HILIC-MS/MS. Individual amino acids concentrations (y-axis) as a function of hydrolysis technique and the number of residues present in BSA. The trendline represents the expected amounts of individual amino acids for protein recovered. Values that are above the trendline represent overestimation and below trendline represents underestimation of specific amino acids

hydrolysis approaches in parallel) for each sample to quantify the maximum number of amino acids. Accounting for amino acid losses is not possible, therefore if one preparation is used to enhance throughput the approach will be more apt to underestimate total protein level.

Alternatively, when assessing a standard or pure protein with known sequence, the measured concentration of all or a subset of amino acids relative to the number of residues can be plotted and the regressed line of best fit used to establish the protein level [55]. Since this latter approach relies on knowledge of the sequence of the protein(s) or mole fractions of the amino acids present in the sample, it is not applicable to complex protein mixtures as in most biological samples. BSA that was hydrolyzed by different methods was also analyzed using the regression approach with measured amino acid amounts established from AccQ-Tag and HILICMS strategies (Fig. 3). Hydrolysis with $\mathrm{HCl}$ including oxidation by $\mathrm{H}_{2} \mathrm{O}_{2}$ (Fig. 3a) resulted in similar best fit lines for AccQ-Tag and HILIC-MS strategies indicating that the amino acid amounts determined from both methods were qualitatively similar and consistent with the values of total protein based on summed amino acid levels in Table 2 (i.e. 80\%, AccQ-Tag; 82\% HILIC-MS for BSA). Possibly if a subset of most reliable amino acids were chosen for quantification the methods would result 
Table 4 Concentration of amino acids as measured by LC-MS/MS with isotope dilution three different hydrolysis methods

\begin{tabular}{|c|c|c|c|c|}
\hline Analyte & $\mathrm{H}_{2} \mathrm{O}_{2}+6 \mathrm{M} \mathrm{HCl}+\beta-\mathrm{ME}$ & $6 \mathrm{M} \mathrm{HCl}+\beta-\mathrm{ME}$ & $\begin{array}{l}4 \mathrm{M} \text { MetS }+0.2 \% \\
\text { tryptamine }\end{array}$ & Reference* \\
\hline Ala & $1.6 \pm 0.13$ & $1.54 \pm 0.08$ & $1.53 \pm 0.05$ & $2.28 \pm 0.16$ \\
\hline Arg & $2.86 \pm 0.07$ & $2.64 \pm 0.08$ & $2.85 \pm 0.24$ & $3.72 \pm 0.31$ \\
\hline Asx & $5.2 \pm 0.24$ & $5.65 \pm 0.38$ & $5.77 \pm 0.46$ & $6 \pm 1.2$ \\
\hline Glx & $7.8 \pm 0.05$ & $8.04 \pm 0.76$ & $8.5 \pm 0.15$ & $10.2 \pm 1.4$ \\
\hline Gly & $1.69 \pm 0.13$ & $1.78 \pm 0.01$ & $1.82 \pm 0.04$ & $2.22 \pm 0.15$ \\
\hline His & $1.25 \pm 0.08$ & $1.55 \pm 0.1$ & $1.72 \pm 0.08$ & $1.22 \pm 0.09$ \\
\hline Ile & $2.59 \pm 0.14$ & $2.62 \pm 0.22$ & $2.37 \pm 0.11$ & $2.31 \pm 0.23$ \\
\hline Leu & $4.62 \pm 0.15$ & $4.56 \pm 0.49$ & $5.13 \pm 0.12$ & $4.03 \pm 0.42$ \\
\hline Lys & $3.49 \pm 0.12$ & $3.69 \pm 0.2$ & $4.03 \pm 0.03$ & $3.2 \pm 0.25$ \\
\hline Phe & $2.22 \pm 0.05$ & $2.93 \pm 0.06$ & $3.21 \pm 0.17$ & $2.54 \pm 0.13$ \\
\hline Pro & $2.73 \pm 0.1$ & $3.05 \pm 0.08$ & $3.22 \pm 0.12$ & $2.71 \pm 0.23$ \\
\hline Ser & $3.03 \pm 0.23$ & $3.09 \pm 0.24$ & $2.92 \pm 0.2$ & $2.69 \pm 0.32$ \\
\hline Thr & $1.97 \pm 0.06$ & $2.52 \pm 0.18$ & $2.33 \pm 0.11$ & $2.02 \pm 0.11$ \\
\hline Val & $2.51 \pm 0.1$ & $2.41 \pm 0.11$ & $2.72 \pm 0.13$ & $2.45 \pm 0.41$ \\
\hline Tyr & $0 \pm 0$ & $2.55 \pm 0.24$ & $3.13 \pm 0.33$ & $1.76 \pm 0.43$ \\
\hline Trp & $0 \pm 0$ & $0 \pm 0$ & $0 \pm 0$ & $0.66 \pm 0.14$ \\
\hline Cys** & $1.14 \pm 0.04$ & $0.81 \pm 0.05$ & $1.02 \pm 0.13$ & $0.74 \pm 0.15$ \\
\hline Met** & $0.97 \pm 0.07$ & $0.74 \pm 0.04$ & $0.91 \pm 0.07$ & $0.69 \pm 0.13$ \\
\hline Total protein & $48.04 \pm 0.99$ & $50.17 \pm 0.89$ & $53.19 \pm 1.47$ & $53.24 \pm 0.36^{* * *}$ \\
\hline
\end{tabular}

Values are expressed as $\mathrm{mg} / 100 \mathrm{mg}$ biomass, amino acids represented by three letter abbreviations

*Values were obtained from NIST certificate of analysis for standard reference material ${ }^{\circledR} 3234$. Variability is expressed as standard error of mean $(n=3)$

${ }^{* *}$ Cysteine was measured as cysteic acid in hydrolysis that involved prior oxidation and as cystine for the other two methods. Similarly, methionine was measured as methionine suloxide upon oxidation and as methionine in the two methods that did not involve prior oxidation

***Total protein reported by NIST used a combination of Kjeldahl, thermal conductivity and pyrolysis methods [48]. Summation of amino acids from NIST reference gives $51.44 \mathrm{mg} / 100 \mathrm{mg}$ biomass

in a similar level of total protein that approached $100 \%$ from either method. However, when other hydrolysis techniques were considered, the HILIC-MS-based isotope dilution approach improved with better accounting for losses that resulted in protein estimates which were 92-95\% accurate; providing a superior strategy to assess protein with unknown amino acid composition (Table 2, Fig. 3).

Quantitative recovery of soybean protein in defatted flour Defatted soybean meal (soy flour), a complex biological sample that is a common source for food and feed protein applications, was obtained as a reference material (SRM-3234) from the National Institute of Standards and Technology (NIST). 16 out of 18 amino acids were quantified to similar levels regardless of the hydrolysis approach (Table 4). Absence of Trp indicated interference from carbohydrates during hydrolysis $[42,52]$ which can be removed through prior processing [56-58]. When $\mathrm{H}_{2} \mathrm{O}_{2}$ was added to oxidize methionine and cysteine, subsequent hydrolysis with $6 \mathrm{M} \mathrm{HCl}$ resulted in halogenation and loss of tyrosine [54]. The total amount of protein from the three hydrolysis methods was 90,94 or $100 \%$ of the reported NIST value (Table 4) with the latter based on a combination of Kjeldahl, thermal conductivity and pyrolysis methods that are each potentially subject to interfering agents and could slightly overestimate the final result. Thus, the HILIC LC-MS/MS method reported here provided a quantitative approach to protein analysis accomplished through a single hydrolysis and processing run without the need for derivatization.

\section{Conclusions}

We developed a combined approach for amino acid compositional analysis and protein concentration determination using HILIC LC-MS/MS with isotope dilution-based quantitation. All twenty amino acids were resolved and quantified using a commercially available mix of labeled amino acids resulting in quantitative determination of protein levels. The method provides a robust and efficient strategy that could be extended to accommodate the detection of non-proteinogenic and modified amino acids [37-39] and can be used for semi-high throughput protein analysis without the need for derivatization 

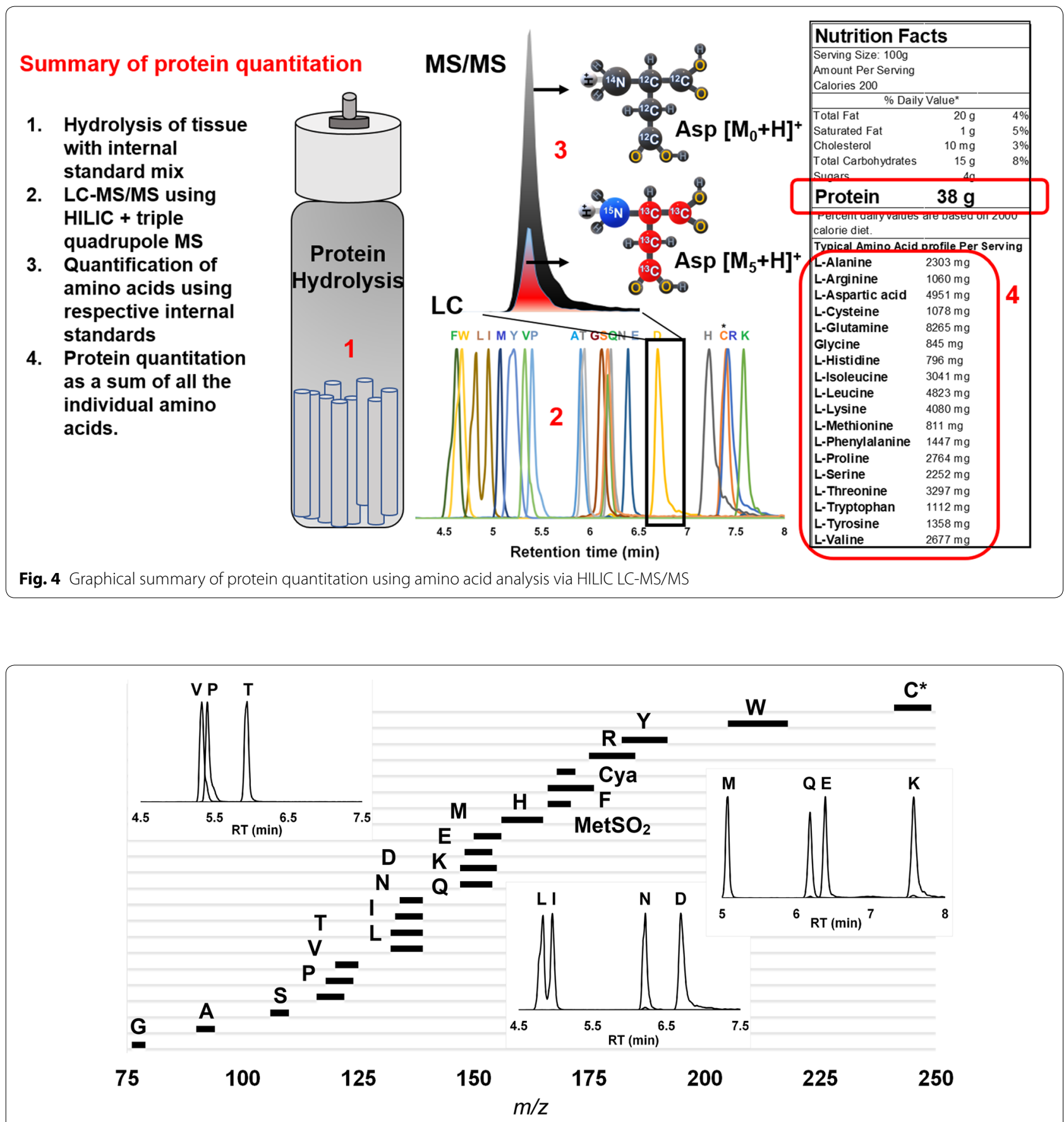

Fig. 5 Overlap in mass ranges, $M_{0}-M_{n}$ where $n$ is the maximum number of ${ }^{13} \mathrm{C}$ and ${ }^{15} \mathrm{~N}$ isotopologues possible for each amino acid. The inset figures indicate separation of amino acids with overlapping masses that can be resolved by HILIC and used to quantify isotopologues. ${ }^{*} C y s t e i n e$ was measured as cystine

after hydrolysis. A graphical summary of the method is presented in Fig. 4. The methane sulfonic acid method of hydrolysis resulted in the highest detected level of labile amino acids; however, since the labile amino acids are present at low levels, all hydrolysis methods resulted in accurate quantification when isotope dilution was employed. HILIC separates most amino acids such that potentially all overlapping isotopologues are resolved (Fig. 5). Alternatively, for combined protein concentration determination and quantification of isotope labeling at the intact protein level, analysis of isotopic fine structure could also be utilized by combining HILIC LC-MS/ 
MS with high resolution mass spectrometry (HRMS) in order to resolve isotope-labeled analytes from isotopelabeled standards using distinct isotopes [59, 60].

\section{Additional files}

Additional file 1: Table S1. Multiple reaction monitoring parameters for amino acids and their respective internal standards on a 6500 QTRAP LC-MS/MS.

Additional file 2: Figure S1. Amino acid quantitation from BSA hydrolyzed using seven different approaches from the literature [21, $56-58,61]$. Peak areas were $\log _{10}$ transformed for relative comparison. Methods included pre-oxidation with either $\mathrm{H}_{2} \mathrm{O}_{2}$ or performic acid, $\beta$-mercaptoethanol as a reducing agent, and presence or absence of phenol as an antioxidant when $6 \mathrm{M} \mathrm{HCl}$ was used for vapor-phase hydrolysis. In addition, a liquid-phase hydrolysis strategy using $4 \mathrm{M}$ methane sulfonic acid with $0.2 \%$ tryptamine was also tested. Labile amino acids including: cysteine, methionine, tryptophan and tyrosine are presented with standard errors from duplicate preliminary experiments.

Additional file 3: Fig. 2. Standard curves generated using a serial dilution (0.1-1000 pmol) of amino acid mixture spiked with ${ }^{13} \mathrm{C},{ }^{15} \mathrm{~N}$ labeled internal standard mix. Ratios of peak areas (analyte vs internal standard) were plotted again ratios of concentrations of amino acids relative to internal standards. *Cysteine was detected as cystine.

\section{Acknowledgements}

The Proteomics and Mass Spectrometry Facility (PMSF) at the Donald Danforth Plant Science Center (DDPSC) is acknowledged for expertise and instrumental support. We thank Justin B. Renaud for his technical expertise.

\section{Authors' contributions}

DKA and BSE conceived and designed the experiments. SK and $J L$ performed experiments and analyzed data. SK, BSE and DKA wrote the manuscript. All authors read and approved the final manuscript.

\section{Funding}

This work was supported by the United States Department of Agriculture, Agricultural Research Service, United States Department of Agriculture, National Institute of Food and Agriculture (USDA-NIFA \#2017-67013-26156), the United Soybean Board \#1820-152-0134, and the National Science Foundation (NSF-MCB \#1616820), and (NSF-DBI \#1427621) the latter provided support for the acquisition of the 6500 QTRAP LC-MS/MS.

\section{Availability of data and materials}

All data generated or analyzed during this study are included in this published article and its supplementary information files.

\section{Ethics approval and consent to participate}

Not applicable.

\section{Consent for publication}

All authors approved the manuscript and provided consent for publication.

\section{Competing interests}

The authors declare no competing interests.

\section{Author details}

${ }^{1}$ Donald Danforth Plant Science Center, St. Louis, MO, USA. ${ }^{2}$ United States Department of Agriculture, Agricultural Research Service, St. Louis, MO, USA.

Received: 12 February 2019 Accepted: 25 April 2019

Published online: 11 May 2019

\section{References}

1. Lowry OH, Rosebrough NJ, Farr AL, Randall RJ. Protein measurement with the Folin phenol reagent. J Biol Chem. 1951;193:265-75.

2. Bradford MM. A rapid and sensitive method for the quantitation of microgram quantities of protein utilizing the principle of protein-dye binding. Anal Biochem. 1976;72:248-54.

3. Smith PK, Krohn RI, Hermanson GT, Mallia AK, Gartner FH, Provenzano MD, Fujimoto EK, Goeke NM, Olson BJ, Klenk DC. Measurement of protein using bicinchoninic acid. Anal Biochem. 1985;150:76-85.

4. Brenna JT, Corso TN, Tobias HJ, Caimi RJ. High-precision continuous-flow isotope ratio mass spectrometry. Mass Spectrom Rev. 1997;16:227-58.

5. Gibson RB. The determination of nitrogen by the kjeldahl method. J Am Chem Soc. 1904;26:105-10.

6. Jones DB. Factors for converting percentages of nitrogen in foods and feeds into percentages of proteins. US Department Agriculture, Circular 1941.

7. Mariotti F, Tomé D, Mirand PP. Converting nitrogen into protein-beyond 6.25 and Jones' factors. Crit Rev Food Sci Nutr. 2008:48:177-84.

8. Simonian MH, Smith JA. Spectrophotometric and colorimetric determination of protein concentration. Curr Protoc Mol Biol. 2006;76:10.11.11-10.11A.19.

9. Noble JE, Bailey MJA. Quantitation of Protein. In: Burgess RR, editor. Methods in Enzymology, vol. 463. Deutscher MP: Academic Press; 2009. p. 73-95.

10. Wiechelman KJ, Braun RD, Fitzpatrick JD. Investigation of the bicinchoninic acid protein assay: identification of the groups responsible for color formation. Anal Biochem. 1988;175:231-7.

11. Kruger NJ. The bradford method for protein quantitation. In: Walker JM, editor. The Protein Protocols Handbook. Totowa, NJ: Humana Press; 2009. p. 17-24.

12. Hobohm U, Houthaeve T, Sander C. Amino acid analysis and protein database compositional search as a rapid and inexpensive method to identify proteins. Anal Biochem. 1994;222:202-9.

13. Roth M, Hampaǐ A. Column chromatography of amino acids with fluorescence detection. J Chromatogr A. 1973;83:353-6.

14. Gardner WS, Miller WH. Reverse-phase liquid chromatographic analysis of amino acids after reaction with o-phthalaldehyde. Anal Biochem. 1980;101:61-5.

15. Rutherfurd SM, Gilani GS. Amino acid analysis. Curr Protoc Protein Sci. 2009;58:11.19.11-37.

16. Spackman DH, Stein WH, Moore S. Automatic recording apparatus for use in chromatography of amino acids. Anal Chem. 1958;30:1190-206.

17. Kutlán D, Molnár-Perl I. Characteristics and stability of the OPA/3-mercaptopropionic acid and OPA/N-acetyl-L-cysteine derivatives of amino acids. Chromatographia. 2001;53:S188-98.

18. Allen DK, Ratcliffe RG. Quantification of isotope label. In: Schwender J, editor. Plant Metabolic Networks. New York, NY: Springer; 2009. p. 105-49.

19. Williams BJ, Cameron CJ, Workman R, Broeckling CD, Sumner LW, Smith JT. Amino acid profiling in plant cell cultures: an inter-laboratory comparison of CE-MS and GC-MS. Electrophoresis. 2007;28:1371-9.

20. Halket JM, Waterman D, Przyborowska AM, Patel RKP, Fraser PD, Bramley PM. Chemical derivatization and mass spectral libraries in metabolic profiling by GC/MS and LC/MS/MS. J Exp Bot. 2005:56:219-43.

21. Dahl-Lassen R, van Hecke J, Jørgensen H, Bukh C, Andersen B, Schjoerring JK. High-throughput analysis of amino acids in plant materials by single quadrupole mass spectrometry. Plant Methods. 2018;14:8.

22. Chaimbault P, Petritis K, Elfakir C, Dreux M. Determination of 20 underivatized proteinic amino acids by ion-pairing chromatography and pneumatically assisted electrospray mass spectrometry. J Chromatogr A. 1999;855:191-202.

23. Aviram LY, McCooeye M, Mester Z. Determination of underivatized amino acids in microsamples of a yeast nutritional supplement by LC-MS following microwave assisted acid hydrolysis. Anal Methods. 2016;8:4497-503.

24. Jander G, Norris SR, Joshi V, Fraga M, Rugg A, Yu S, Li L, Last RL. Application of a high-throughput HPLC-MS/MS assay to Arabidopsis mutant screening; evidence that threonine aldolase plays a role in seed nutritional quality. Plant J. 2004;39:465-75.

25. Gu L, Jones AD, Last RL. LC - MS/MS assay for protein amino acids and metabolically related compounds for large-scale screening of metabolic phenotypes. Anal Chem. 2007;79:8067-75. 
26. Harder U, Koletzko B, Peissner W. Quantification of 22 plasma amino acids combining derivatization and ion-pair LC-MS/MS. J Chromatogr B. 2011;879:495-504.

27. Alpert AJ. Hydrophilic-interaction chromatography for the separation of peptides, nucleic acids and other polar compounds. J Chromatogr A. 1990;499:177-96.

28. Buszewski B, Noga S. Hydrophilic interaction liquid chromatography (HILIC) - a powerful separation technique. Anal Bioanal Chem. 2012;402:231-47.

29. Chen P, Li W, Li Q, Wang Y, Li Z, Ni Y, Koike K. Identification and quantification of nucleosides and nucleobases in Geosaurus and Leech by hydrophilic-interaction chromatography. Talanta. 2011;85:1634-41.

30. Neville DCA, Alonzi DS, Butters TD. Hydrophilic interaction liquid chromatography of anthranilic acid-labelled oligosaccharides with a 4-aminobenzoic acid ethyl ester-labelled dextran hydrolysate internal standard. J Chromatogr A. 2012;1233:66-70.

31. Joyce R, Kuziene V, Zou X, Wang X, Pullen F, Loo RL. Development and validation of an ultra-performance liquid chromatography quadrupole time of flight mass spectrometry method for rapid quantification of free amino acids in human urine. Amino Acids. 2016:48:219-34.

32. Bathena SP, Huang J, Epstein AA, Gendelman HE, Boska MD, Alnouti Y. Rapid and reliable quantitation of amino acids and myo-inositol in mouse brain by high performance liquid chromatography and tandem mass spectrometry. J Chromatogr B. 2012;893-894:15-20.

33. Krumpochova P, Bruyneel B, Molenaar D, Koukou A, Wuhrer M, Niessen WMA, Giera M. Amino acid analysis using chromatography-mass spectrometry: An inter platform comparison study. J Pharm Biomed Anal. 2015;114:398-407.

34. Mülleder M, Bluemlein K, Ralser M. A high-throughput method for the quantitative determination of free amino acids in saccharomyces Cerevisiae by hydrophilic interaction chromatography-tandem mass spectrometry. In: Andrews B, Boone C, Davis TN, Fields S, editors. Budding Yeast: A Laboratory Manual. New York: Cold Spring Harbor Laboratory Press; 2016. p. 608-13.

35. Gao J, Helmus R, Cerli C, Jansen B, Wang X, Kalbitz K. Robust analysis of underivatized free amino acids in soil by hydrophilic interaction liquid chromatography coupled with electrospray tandem mass spectrometry. J Chromatogr A. 2016;1449:78-88.

36. Tsochatzis ED, Begou O, Gika HG, Karayannakidis PD, Kalogiannis S. A hydrophilic interaction chromatography-tandem mass spectrometry method for amino acid profiling in mussels. J Chromatogr B. 2017;1047:197-206

37. Guo S, Duan J, Qian D, Tang Y, Qian Y, Wu D, Su S, Shang E. Rapid determination of amino acids in fruits of Ziziphus jujubaby hydrophilic interaction ultra-high-performance liquid chromatography coupled with triplequadrupole mass spectrometry. J Agric Food Chem. 2013;61:2709-19.

38. Zhou G, Pang H, Tang Y, Yao X, Mo X, Zhu S, Guo S, Qian D, Qian Y, Su S, et al. Hydrophilic interaction ultra-performance liquid chromatography coupled with triple-quadrupole tandem mass spectrometry for highly rapid and sensitive analysis of underivatized amino acids in functional foods. Amino Acids. 2013:44:1293-305.

39. Prinsen HCMT, Schiebergen-Bronkhorst BGM, Roeleveld MW, Jans JJM, de Sain-van der Velden MGM, Visser G, van Hasselt PM, Verhoeven-Duif NM. Rapid quantification of underivatized amino acids in plasma by hydrophilic interaction liquid chromatography (HILIC) coupled with tandem mass-spectrometry. J Inherit Metab Dis. 2016;39:651-60.

40. Stokvis E, Rosing H, Beijnen JH. Stable isotopically labeled internal standards in quantitative bioanalysis using liquid chromatography/ mass spectrometry: necessity or not? Rapid Commun Mass Spectrom. 2005;19:401-7.

41. Darragh AJ, Garrick DJ, Moughan PJ, Hendriks WH. Correction for amino acid loss during acid hydrolysis of a purified protein. Anal Biochem. 1996;236:199-207.
42. Ng LT, Pascaud A, Pascaud M. Hydrochloric acid hydrolysis of proteins and determination of tryptophan by reversed-phase high-performance liquid chromatography. Anal Biochem. 1987;167:47-52.

43. Puchała R, Piór H, von Keyserlingk M, Shelford JA, Barej W. Determination of methionine sulfoxide in biological materials using HPLC and its degradability in the rumen of cattle. Anim Feed Sci Technol. 1994;48:121-30.

44. Rayner CJ. Protein hydrolysis of animal feeds for amino acid content. J Agric Food Chem. 1985;33:722-5.

45. Rutherfurd SM. Accurate determination of the amino acid content of selected feedstuffs. Int J Food Sci Nutr. 2009;60:53-62.

46. Weiss M, Manneberg M, Juranville J-F, Lahm H-W, Fountoulakis M. Effect of the hydrolysis method on the determination of the amino acid composition of proteins. J Chromatogr A. 1998;795:263-75.

47. Fountoulakis M, Lahm H-W. Hydrolysis and amino acid composition analysis of proteins. J Chromatogr A. 1998;826:109-34.

48. Certificate: SRM 3234 - Soy Flour. https://www-s.nist.gov/srmors/view_ cert.cfm?srm=3234. Accessed Aug 2018.

49. Frank MP, Powers RW. Simple and rapid quantitative high-performance liquid chromatographic analysis of plasma amino acids. J Chromatogr, B: Anal Technol Biomed Life Sci. 2007;852:646-9.

50. Krömer JO, Fritz M, Heinzle E, Wittmann C. In vivo quantification of intracellular amino acids and intermediates of the methionine pathway in Corynebacterium glutamicum. Anal Biochem. 2005;340:171-3.

51. Imsande J. Selection of soybean mutants with increased concentrations of seed methionine and cysteine. Crop Sci. 2001;41:510-5.

52. Hugli TE, Moore S. Determination of the tryptophan content of proteins by ion exchange chromatography of alkaline hydrolysates. J Biol Chem. 1972;247:2828-34.

53. Simpson RJ, Neuberger MR, Liu TY. Complete amino acid analysis of proteins from a single hydrolysate. J Biol Chem. 1976;251:1936-40.

54. Nissen S. Amino acid analysis in food and in physiological samples. In: Nissen S, editor. Modern Methods in Protein Nutrition and Metabolism. New York: Academic Press; 1992. p. 1-8.

55. Schegg KM, Denslow ND, Andersen TT, Bao Y, Cohen SA, Mahrenholz AM, Mann K. Quantitation and identification of proteins by amino acid analysis: ABRF-96AAA collaborative trial. In: Marshak DR, editor. Techniques in Protein Chemistry, vol. 8. New York: Academic Press; 1997. p. 207-16.

56. Norikoshi $R$, Imanishi $H$, Ichimura K. A simple and rapid extraction method of carbohydrates from petals or sepals of four floricultural plants for determination of their content. J Jpn Soc Hortic Sci. 2008;77:289-95.

57. Maness N. Extraction and analysis of soluble carbohydrates. In: Sunkar R, editor. Plant Stress Tolerance: Methods and Protocols. Totowa, NJ: Humana Press; 2010. p. 341-70.

58. Smith D, Paulsen GM, Raguse CA. Extraction of total available carbohydrates from grass and legume tissue. Plant Physiol. 1964;39:960-2.

59. Allen DK. Assessing compartmentalized flux in lipid metabolism with isotopes. Biochimica et Biophysica Acta (BBA) - Molecular and Cell Biology of Lipids. 2016;1861:1226-42.

60. Allen DK. Quantifying plant phenotypes with isotopic labeling and metabolic flux analysis. Curr Opin Biotechnol. 2016;37:45-52.

61. Prokopenko Y, Jakštas V, Žvikas V, Georgiyants V, Ivanauskas L. Hilic MS/MS determination of amino acids in herbs of Fumaria schleicheri L., Ocimum basilicum L., and leaves of Corylus avellana L. Nat Prod Res. 2018. https:// doi.org/10.1080/14786419.2018.1477145

\section{Publisher's Note}

Springer Nature remains neutral with regard to jurisdictional claims in published maps and institutional affiliations. 